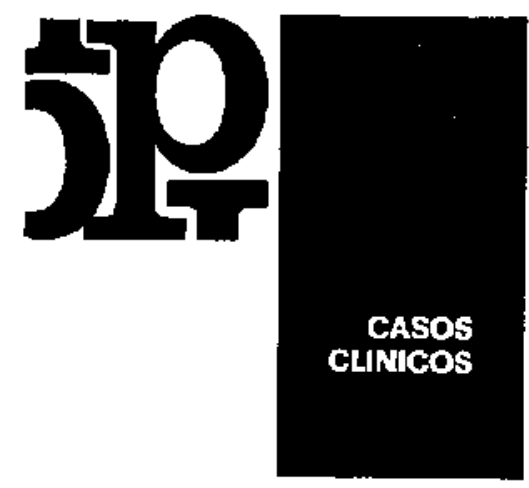

\title{
Miositis osificante generalizada progresiva congénita
}

\author{
DRES.: FRANCISCO PARADA B. *, DAVID MIRKIN W. *t.
}

Ocasionalmente se publican en la literatura médica casos de miositis osificante (M. O.) describiendo el cuadro clínico, su sintomatología, los intentos de tratamiento y sus fracasos y la ignorancia sobre su etiopatogenia. El primer caso descrito Je esta enfermedad, fue publicado por el Dr. M. Guy Patin, de la Facultad de Medicina de Paris, en 1692; Jo llamó "la mujer de madera" (1). Otros investigadores que contribuyeron al conocimiento de esta enfermedad, fueron Hawkins (1844) que publicó un estudio histopatológico; Gerber (1875) y Helferich (1879) que describieron las malformaciones de pulgares $\mathrm{y}$ ortejos y Juengling (1912) que señaló la presencia de otras malformaciones asociadas; pero fue Ernst Münchmeyer (1869) quien la individualizó como una entidad clínica. $(1,2,6)$. Parece ser una enfermedad que afecta más a los anglosajones $y$ menos a los pueblos latinos.

En la literatura médica nacional a nuestro alcance, encontramos un caso publicado por $\mathbf{H}$. Jaeger (1942), que parece ser el primero. (1). Se trataba de un niño al que a los 7 meses le encontraron pequeños tumores en la nuca y región dorsal; a los 5 años ya tenía la cabeza y los miembros superiores fijos, compromiso de los masticadores, cifosis dorsal y microdactilia de los ortejos mayores. El segundo caso fue descrito por R. Burdach (1953). El paciente fue tratado con corticoides, lo que impidió la aparición de nuevos brotes. (3). Suárez, Saavedra y Jeria (1969) publicaron otro caso de $\mathbf{M}$. O. similar en sus signos clínicos, y propusieron el tratamiento quirúrgico para liberar los miembros, al mismo tiempo que administrat corticoides y EDTA para cvitar el efecto del rebote (4).

\footnotetext{
* Departamento le Cirugía. Hospital Ruberto del Rlo. * Servicio de Anatomia Patológica. Hospital Roberto del Río.
Santiagu de Chile.
}

La miositis osificante, o Enfermedad de Münchmeyer, es una osificación heterotópica, metaplásica, generalizada, progresiva, congénita del tejido conjuntivo del aparato locomotor. $(5 ; 6)$. Se caracteriza por la transformación en hueso similar al normal del tejido intersticial del músculo, fascias, aponeurosis, ligamentos y tendones. Este tejido de neoformación puede estar unido o no al periostio. Es una enfermedad rara. En la literatura nacional hemos encontrado tres casos publicados y en la literatura médica mundial, la revisión más completa se debe a Lutwak (1964), que encuentra 260 casos a los que agrega cuatro (7).

Comienza frecuentemente antes de los tres años. Se considera congénita por la mayoría de los autores. Taradori y Masarani (1939) publicaron cinco casos de comienzo intrauterino. (cit. 6). La causa de la afección es desconocida. Las hipotesis para explicar el origen de esta enfermedad son múltiples: inflamatorias, embrionarias o congénitas, endócrinas, inmunitarias o enzimáticas.

Selye (1962) sustenta la teoría de la "calcifilaxia", que sería la calcificación masiva pero electiva de tejidos e incluso órganos, como respuesta a estímulos diversos. Adninistre un hipercalcómiante sistémico como la vit. D., la hormona paratiroidea, u otros que prepara los tejidos, para después provocar calcificaciones selectivas, mediante la administración de provocadores como diversas sales metálicas, clara de huevo, o un traumatismo cutáneo, en las ratas ya sensibilizadas.

La acción selectiva se obtiene mediante la administración intravenosa de agentes provocadores que tengan una afinidad definida por los distintos órganos (bazo, páncreas, piel, articulaciones, etc.). (5).

Desde el punto de vista histológico la enfermedad se caracteriza por la formación de hueso 
heterotópico, usualmente en el tejido conjuntivo cojlágeno de raúsculo esquelético, en tendones, ligamentos, fascias y aponeurosis. (Fig. 4 b).

En el mecanismo de formación osea parece producirse una cadena de eventos iniciada por una proliferación excesiva de colagenoblastos. Se piensa que la hemorragia intersticial jugaría un papel importante en el tipo post traumático y la necrosis muscular también podría estimular esta actividad.

El examen microscópico de las lesiones en los estadios tempranos ha revelado reacción inflamatoria edematosa, frecuentemente con infiltración celular exudativa. Este tipo de reacción es frecuentemente encontrado en lugares de respuesta tisular alérgica por lo que se ha sugerido la posibilidad de que la hipersensibilidad podría tener que ver en los tipos idiopáticos y progresivos.

Grandes masas de colágeno son producidas por esta proliferación celular edematosa y este colágeno es aparentemente diferente del normal en tanto acepta la deposición de sales de calcio.

Cuando la actividad osteoblástica es florida con osteoblastos numerosos jóvenes e hipercromáticos entre masas irregulares de osteoide puede ser imposible hacer la distinción entre miositis osificante y osteosarcoma en base sólo al aspecto microscópico, (8). En general el tejido óseo formado en la $\mathrm{M}$. $\mathrm{O}$. es más normal y regular y la lesión está mejor circunscrita. La presencia de células musculares viables entre los osteoblastos proliferantes y las espículas de hueso son de gran ayuda para establecer un diagnóstico microscópico ya que el tumor tiende a destruir el músculo a medida que avanza.

Fine y Stout (9) han revisado la incidencia de osteosarcoma osteogénico como complicación de la miositis osificante encontrando doce de tales casos. Es probable que se refieran a casos de miositis osificante circunscrita. El osteosarcoma en la M. O. tiene la misma microscopía, curso y pronóstico que los del osteosarcoma de hueso (8).

La M. O. puede seguir un curso agudo, subagudo o insidioso y evoluciona en brotes sucesivos. Se pueden considerar tres etapas: a) de las tumefacciones musculares o tejidos blandos: b) del osteoma y c) de las actitudes viciosas. Estas tres etapas están en relación estrecha con la histopatología de la enfermedad.

La tumefacciones de los tejidos blandos evoIucionan con rubor y calor local, dolor a la palpación, semejando un proceso inflamatorio corriente y que sigue el trayecto de un músculo; no se aprecian alteraciones hematológicas de importancia y la sedimentación es baja.

Los grupos musculares que se afectan primero son por lo general los de la parte alta dorsal y de la nuca para avanzar en sentido descendente y excéntrico hacia el tronco y extremidades. Estas tumoraciones blandas aumentan de consistencia, constituyendo la segunda etapa, del osteoma. Las láminas o tumores de tejido óseo siguen el trayecto de un músculo, tendones o aponeurosis, inmovilizando articulaciones y segmentos comprometidos, las que tarde o temprano provocan las actitudes viciosas. Los músculos oculares, diafragma, lengua, corazón y esfínteres, no se comprometen.

Acompañando a esta transformación de tejidos blandos en hueso, y necesario para completar la constitución de esta entidad clínica, están presentes las malformaciones de dedos y ortejos. Las más frecuentes son las del ortejo mayor $(87 \%)$, del pulgar $(51 \%)$ y en menor proporción los otros ortejos y dedos. El ortejo mayor puede estar afectado de microdactilia, hallux valgus, anquilosis interfalángica, ausencia de una falange, hipoplasia del primer metatarsiano, fusión del primer metatarsiano con la primera falange, etc .También hay asociación con otras anomalías congéritas, como las del aparato genital (4\%), neurológicas $(4 \%)$ y cardíacas $(2 \%)$.

Los exámenes de laboratorio, incluyendo los que están ligados al metabolismo del calcio, son prácticamente normales.

Para la aparición de signos radiológicos de osificación pueden transcurrir dos o tres meses desde que se comprueba la presencia de tumoraciones blandas. Al comienzo se observa una sombra homogénea paralela al eje muscular y distante del hueso normal y que posteriormente compromete todo el músculo, y están presentes los signos de osificación radiológica como la cortical, la estructura medular y trabecular. Además es necesaria la búsqueda de las malformaciones de ortejos y dedos, que siempre, las revela la radiología. (Fig. 1 b y 2 b).

La enfermedad evoluciona por brotes, a veces con intervalos de meses o años, de curso progresivo e invalidante. Los puentes óseos que fijan las articulaciones impiden que el enfermo se valga por sí mismo; el compromiso de los músculos respiratorios provocan una mala ventilación pulmonar que lleva a continuas infecciones pulmonares; cuando se toman los músculos masticadores que impiden la alimentación, sobrevendrá la inanición. El pronóstico es malo.

El diagnóstico diferencial se hace con otras calcificaciones mioarticulares (10). Estas calcificaciones se pueden dividit en dos grandes grupos:

1) las con formación de tejidos óseos, y 2) con depósito de calcio. En el primer grupo tenemos la miositis osificante generalizada y la circunscrita. A su vez la generalizada puede ser progresivil y congénita o Enfermedad de Münchmeyer, que es la que estamos describiendo, y otra generalizada que es secundaria a infecciones, especialmente a tétanos y poliomielitis. Entre las osifica- 


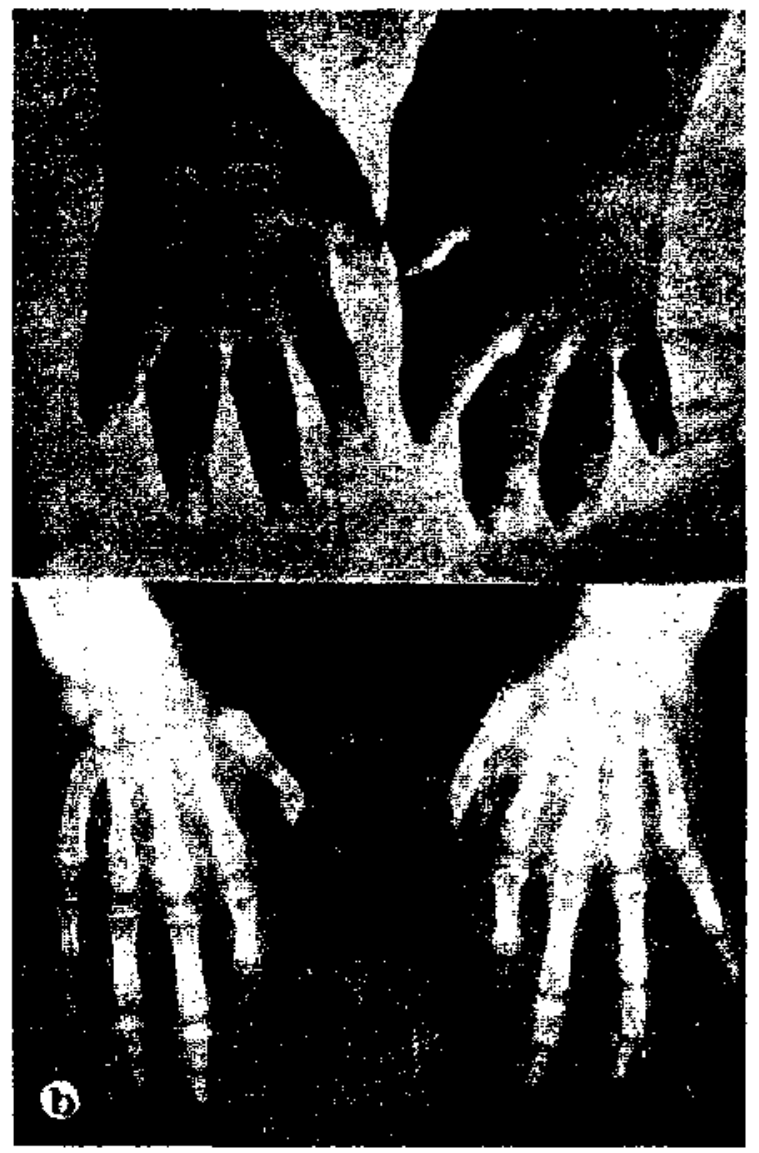

Fig. 1. a) Deformitad marcacla de arrtyos pulgares.

b) Hipoplasia de meiacarpianos y falanges de ambos pulgates. Aasencia de segundas falanges de indices y meiniques.

ciones circunseritas se encuentra la Exostosis múltiple hereditaria. Esta enfermedad es más frecuente, más conocida y de buen pronóstico, y en ella el tratamiento quirúrgico es eficaz aunque las exostosis tienden a reproducirse. Nuestro caso se confundió durante dos años con esta entermedad y se hicieron resecciones quirúrgicas que perjudicaron al enfermo.

En el segundo grupo, sólo hay depósito de calcio y no hueso organizado. Puede haber alteraciones del metabolismo del calcio como en eI hiper e hipoparatiroidismo, en la hipervitaminosis $D$ y en la osteodistrofia hereditaria de Albright. También hay depósito de calcio en la Calcinosis que puede ser a su vez universal o localizada; esta última puede ser idiopática o asociada a dermatomiositis, a esclerodermia, a Sindrome de EhlerDanlos o a Sindrome de Werner.

Se han intentado múltiples trataunientos médicos, (1) como las dictas hidrocarbonadas, acidificantes y secundariamente descalcificantes; (11) regimenes pobres en fósforo, calcio y vitamina D. Se ha usado citrato de sodio, ácidos fosfórico, láctico, clorhídrico, por semejanzas con e] tratamiento a veces favorable de la calcinosis universalis. (12). Se ha empleado extracto paratiroideo, hormonas sexuales, Etilendiaminotricloroacético (EDTA) y corticoides. Los agentes físicos como la diatermia y ultratermia no han surtido efecto y la reontgenterapia local ha sido proscrita por su nulo efecto y por que puede provocar la malignización del proceso (13). Las intervenciones paliativas para liberar articulaciones o nervios o corregir deformaciones, han fracasado, pues de nuevo se reproducen, rápidamente y alcanzan un desarrollo mayor que el tumor que se extirpó. $(14,15)$. Aún las biopsias en músculos sanos pueden provocar osificaciones. (16).

Caso Clinjco. Niño de 5 años 3 ineses de edad que presenta una masid lumoral isquiática desde el nacimiento.

La historia clínica es escueta. Sólo refiere que la madre ha notado desde el nacimiento, masas duras en

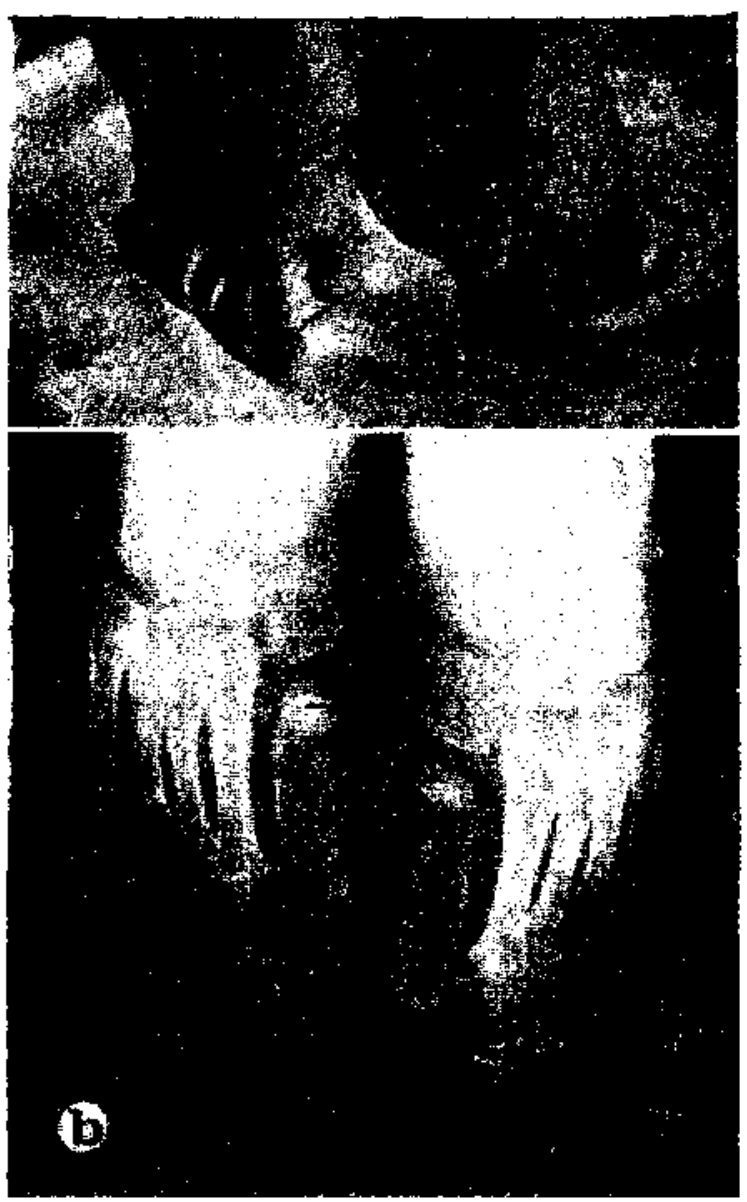

I ip. 2. a) Dedos de los piles mallormades con apariencia te armputación dk los ortejus.

(b) Dulatmidad marwada de cuneiformes internos y primeros metatarsianos qus aparcen ensanchados iransparenter, Ausencia de Ialanges de primero y cuarto ortcjos. 
cl stútco izquierdo las cuales han aumentado con la edad. En diferentes regiones del cuerpo fueron apareciendo otros tumores de crecimiento progresivo. (Fig. 3a). En el examen físico de ingreso se comprucba tucen estado general y lucide\%, sin defficit mental.

Cabeza: n'e. Cuejlo: discreta linitación de la fhexión. Algunos ganglios pequeños a lo largo de los esternocleidemastoideos. 'Tórax simétrico. Corazón: tonos normales, ro se escuchan ruidos agregados. Pulmones: percusión y auscultación nomales. Abdomen: blando, depresible, no se palpa hígado ni bazo. Genitales: hipospadias y ectopi: lesticular bilateral alta. Extremidades: en el Łlúteo izquierdo se palpan masas duras adherentes a la piel. la cual está como fibrosadil.

En el musto derecho se palpa zona dura de consistencia ósea, que parece corresponder a callo de fractura. (Fig. 3b). En el tercio inferior del antebrazo izquierdo hay otra malsa redondeada de $2 \mathrm{~cm}$. de diámetro, durar adherente a planos profundos.

Las radiografías demuestran exostosis múltiples de extremidades superiores e inferiores. (Fig. 4a). El hemograma revela una Jeucocitosis de 16.800 y linfocitos 59. La sedimentación globulil es de $22 \mathrm{~mm}$. en I hora.

Se interviene sobre el tumor perineal que es de consistencia ósea y se envía a biopsia.

Se dio de alta il los Jos días con el diagnóstico de neurofibromatosis, exostosis múltiples, hipospadia, desconociéndose el informe histológico que sugería el diagnóstico de M. 0 .

Reingresó al año siguiente porque la cxostosis isquiáfica se ha reproducido, alcanzando un mayor tamaño. Se cataloga cono Exostosis múltiple ¿familior? pero se deja constancia de otras malformaciones como braquidactilia con atrofia de pulgares $y$ ortejos (Fig. 1a y 2a) además de la hipospadia y la ectopia testicular. En esta hospitalización se resecan las exostosis isquiática, la del muslo derecho y región dorstl izquierda. y
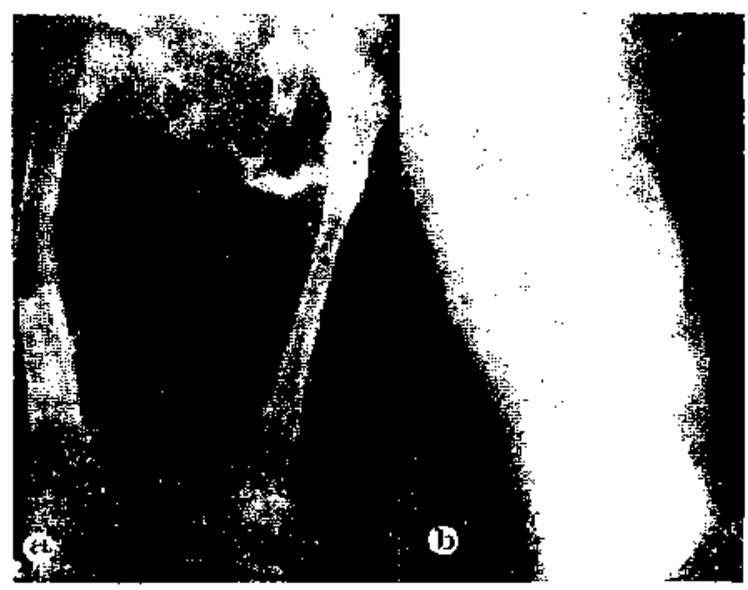

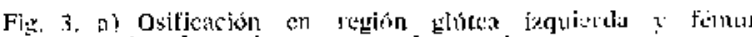
clerecho más grusso e jricursado.

b) Vista lateral de osificación ctt fómur derecho aț̦iacunte at periostio.

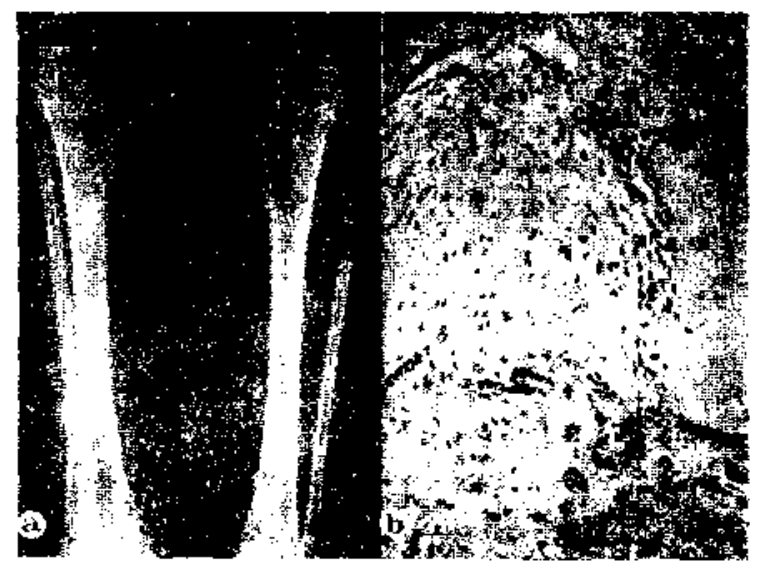

l:i.. 1. ai Exastosis simetricas en metalisis proximales de ambas tibias (flochas).

(1) Micrutulugralia que muestra la transformación prosresira de colágenosblastos en oskeoblastos. $H$ : hueso. He'maluxilina-cosina. $160 \mathrm{X}$.

se interviene sobre la hipospadia (primer tiempo) y fa ectopia testicular.

En su tercer reingreso (1974), se observa que han recidivado las exostosis del fémur y región isquiática, pero se ha agregado rigidez de la columna cervical.

En esta ocasión se tomó mayor interés en el caso clínico y se decidió hacer un mayor estudio para preciśar el diagnóstico. Basándose en estas recidivas de rápido crecimiento, y la aparición de otros tumores, como los que se palpan en los músculos del cuello, especialmente trapecio, revisamos las entidades patológicas que se engloba en el extenso capitulo de las calcificaciones mioariculares. Abandonamos el diagnóstico de Evostosis múltiple familiar, porque sobraban elementos para csta enfermedad.

Discusion. Estc caso calza perfectamente en la cntidad clínica denominda Miositis osificante generalizada, progresiva, congénita. En esta enfermedad siempre hay malformaciones de manos y pies, especialmente de dedos y ortejos y puede haber otras malformaciones, como en el caso presente en quic se encuentran además hipospadia y cetopia testicular bilateral. Las tres biopsias revetan osificación no sarcomatosa. Es congénita, pues la madre vio y palpó masas duras desde el nacimiento, las que crecieron lentamente y se han generatizado. Si a esto se agrega que los exámenes de laboratorio, especialmente los que se relacionan con cl metabolismo del calcio, son prácticamente normiales, se confinna el diagnóstico de Miositis osificante o Enfermedad de Münchmeyer.

Se considera oportuno considerar la dosificación do calcificantes cono la vitamina $D$ que en nuestro medio se suministra en forma masiva (tres golpes vitamínicos en el primer año) en lugares con intensa radiación solar como las zonas norte y central pari así evitar la posibilidad de calcificaciones iatrogénicas. (17). 


\section{RESUMEN}

Niño de 5 años que presenta una tumoración isquiatica desde el nacimiento y otros tumores de crecimiento progresivo en diferentes regiones del cuerpo. La radiología demuestra múltiples exostosis y otras malformaciones óseas agregadas. El estudio histológico de las biopsias revela osificación de tejido conjuntivo extráseo.

Se sugiere evitar nuevas resecciones de sus exostosis, las cuales se han reproducido rápidamente, adquiriendo un tamaño mayor.

Se revisa la literatura nacional y extranjera sobre miositis osificante.

\section{SUMMARY}

The case of a male child 5 years 3 month old presenting an ischiatic turnor since birth is related. Furthermore other tumors in different regions of the body were progressively growing. Besides he has urogenital malformations (hypospadias, cryptorchid). X-ray films show multiple exostosis and aggregated osseous malformations. Biopsies reveal ossification of extra-osseous conective tissue. Do not resecting the exostosis is suggested in order to avoid the rapid relapse of them getting a greater size further.

\section{REFERENCIAS}

1.-Jaeger, H.: Miositis osificante múltiple progresiva o Enf. đe Münchmeyer. Rev. Chil. Pediat. 13: $785-803,1942$.

2.-Tratado Enciclopédica. Enfermedades de la Infancia. M. V. Pfaudler y A. Schlossmann. Tomo IV. Pág. 594, Francisco Seit 1934.

3.-Burdach, R.: Miositis osificante progresival. Rev. Chil. Pediat. 24: 387-394, 1953.
4.-Suártz, H. Suavedra, C, Jeria. H.: Miositis osifjcante. Rev. Chil. Pediat. 40: 883-893, 1969.

5.--López Sendon, J. L.: Miositis osificante progresiva múltiple. Rev. Clin. Esp. 11: 437-442, 1968.

6.- Rapado, Ballina, Romero y Jiménez Casado: Miositis osificante progresiva congénita (Enf. de Münchmeyer). Rev. Clin. Esp. 96: 246-250, 1965.

7.- Lutwak, L.: Myositis ossificans progresiva. Amer. J. Med. 37: 269-293, 1964.

8.-Aegerter E., Kirkpatrickk J. A.: Orthopedic diseases. Saunders 1968. Pág. 876.

9.- Fine, G., Stout, A. P.: Cancer. 9: 1027, 1956, en Aegerter y Kirkpatrick. Pág. 878.

10.-Catel, W.: Diagnóstico en Pediatría. Salvat. 1966. Pág. 143-148.

11._Current Pediatric Therapy. Saunders 1970. Pág. 651.

12,-González de Langarica, R.: Calcinosis universal. Rev. Chil. Pediat. 26: 426-430, 1955.

13.-Shanoff. L. B.; Spira M., Hardy B.: Myositis ossificans: Evolution to osteogenic sarcoma. Am. J. Surg. 113: 537-541, 1967.

14.-Textbook of Surgerv. Christopher, F. Saunders 1943. Pág. 170.

15.- Campbell, w. C.: Cirugía ortopédica. Intermédica, 1965. Pág. 1505.

16.- Arroyo de la Fuente y cols.: Miositis osificante progresiva. Rev. Clin. Esp. 102: 52-55, 1966.

17.-Cooke, R. E.: Bases Biológicas en la práctica pediátrica. Salvat, 1970 . 